ISSN 1561-8358 (Print)

ISSN 2524-244X (Online)

УДК 666.797

https://doi.org/10.29235/1561-8358-2019-64-4-413-418

Поступила в редакцию 22.11.2018

Received 22.11.2018

\title{
С.М. Азаров
}

Белорусский национальный технический университет, Минск, Беларусь

\section{ВЛИЯНИЕ МОДИФИЦИРУЮЩИХ ПОКРЫТИЙ НА ДИЭЛЕКТРИЧЕСКУЮ ПРОНИЦАЕМОСТЬ КЕРАМИЧЕСКИХ МАТЕРИАЛОВ С КОМПОЗИЦИОННЫМИ ПОКРЫТИЯМИ}

\begin{abstract}
Аннотация. Представлены результаты исследования особенностей модифицирования алюмосиликатной керамики суспензией фторопласта, алюмофосфатного связующего (АФС), неводных композиций компонентов полиуретана. Образцы алюмосиликатной керамики для исследований получали технологическими приемами, включающими операции подготовки шихты, прессование образцов, предварительный отжиг и спекание при температуре $1200-1350{ }^{\circ} \mathrm{C}$. В качестве исходных компонентов были выбраны полидисперсные порошки алюмосиликатов, полученные измельчением отходов фарфорового производства (фарфоровой посуды, ГОСТ 28390-89), легкоплавкое глинистое сырье. Модифицирование поверхности алюмосиликатных материалов проводили путем импрегнации водных композиций на основе суспензии фторопласта и АФС, неводных композиций компонентов полиуретана, используемых при получении пенополиуретана и 5\%-ного раствора полиэтилгидросилоксана в толуоле с формированием на поверхности керамических материалов композиционных покрытий. Показано, что нанесение пленочных органических покрытий (на основе полиуретана, алюмофосфатного связующего и суспензии фторопласта-4Д, полиэтилгидросилоксана) приводит к формированию многослойного диэлектрического материала, в котором присутствуют поверхности раздела, отделяющие области с различными диэлектрическими свойствами. При наличии внешнего электрического поля создаются условия для миграционной поляризации между кристаллической фазой основы и аморфной фазой покрытия, обусловленной перераспределением свободных зарядов в объеме композита. Причем химическое взаимодействие АФС с керамикой приводит к сглаживанию рельефа поверхности алюмосиликатной основы и заращиванию глубоких пор. Композит «алюмосиликат - покрытие АФС-фторопласт» отличается от остальных материалов прежде всего тем, что алюмофосфатное связующее покрытия химически реагирует с керамической основой. Ионы примеси, внесенные при нанесении покрытия, его композиционная структура, а также гетерогенность границы раздела определяет выраженную частотную зависимость $\varepsilon$ и $\operatorname{tg} \delta$, а также большие диэлектрические потери композита в сравнении с исходным алюмосиликатным материалом.

Ключевые слова: алюмосиликатная керамика, суспензия фторопласта, алюмофосфатное связующее (АФС), неводные композиции компонентов полиуретана, структура покрытия

Для цитирования: Азаров, С. М. Влияние модифицирующих покрытий на диэлектрическую проницаемость керамических материалов с композиционными покрытиями / С. М. Азаров // Вес. Нац. акад. навук Беларусі. Сер. фіз.тэхн. навук. - 2019. - Т. 64, № 4. - С. 413-418. https://doi.org/10.29235/1561-8358-2019-64-4-413-418
\end{abstract}

\section{S. M. Azarau}

Belarusian National Technical University, Minsk, Belarus

\section{INFLUENCE OF MODIFYING COATINGS ON DIELECTRIC PERMITTIVITY OF CERAMIC MATERIALS WITH COMPOSITE COATINGS}

\begin{abstract}
The results of research of features of modification of aluminosilicate ceramics by suspension of fluoroplastic, aluminophosphate binder (AFS), non-aqueous compositions of polyurethane components, are presented. Samples of aluminosilicate ceramics for research were obtained by technological methods, including batch preparation operations, sample pressing, pre-annealing and sintering at a temperature of $1200-1350{ }^{\circ} \mathrm{C}$. Polydisperse powders of aluminosilicates obtained by grinding waste of porcelain production (porcelain ware, GOST 28390-89); low-melting clay raw materials were selected as initial components. Modification of surface of aluminosilicate materials was carried out by impregnation of aqueous compositions based on a suspension of fluoroplastic and aluminophosphate binder (AFS), non-aqueous compositions of polyurethane components used in the preparation of polyurethane foam and $5 \%$ solution of polyethylene hydrosiloxane in toluene with the formation of composite coatings on the surface of ceramic materials. It is shown that the application of organic film coatings (based on polyurethane, aluminophosphate binder and a suspension of fluoroplastic-4D, polyethylene hydrosiloxane) leads to formation of a multilayer dielectric material in which there are interface surfaces separating areas with different dielectric
\end{abstract}

(C) Азаров С.М., 2019 
properties. In the presence of an external electric field, conditions are created for migration polarization between the crystalline phase of the substrate and the amorphous phase of the coating, due to the redistribution of free charges in the volume of the composite. Moreover, the chemical interaction of AFS with ceramics leads to the smoothing of the surface relief of the aluminosilicate base and the overgrowth of deep pores. Composite "aluminosilicate - AFS-fluoroplastic coating" differs from other materials, primarily in that aluminophosphate binder coating chemically reacts with the ceramic base. The impurity ions introduced during coating application, its composite structure, as well as the heterogeneity of the interface determine the pronounced frequency dependence $\varepsilon$ and tg $\delta$, as well as large dielectric losses of the composite in comparison with the original aluminosilicate material.

Keywords: aluminosilicate ceramics, fluoroplastic suspension, aluminophosphate binder, non-aqueous compositions of the components of the polyurethane, coating structure

For citation: Azarau S.M. Influence of modifying coatings on dielectric permittivity of ceramic materials with composite coatings. Vestsi Natsyyanal'nai akademii navuk Belarusi. Seryya fizika-technichnych navuk = Proceedings of the National Academy of Sciences of Belarus. Physical-technical series, 2019, vol. 64, no. 4, pp. $413-418$ (in Russian). https://doi.org/10.29235/1561-8358-2019-64-4-413-418

Введение. В настоящее время для изготовления электроизоляционных материалов используются в основном достаточно дорогие импортные порошки каолина с размером частиц менее 10 мкм [1]. В Республике Беларусь разработана технология получения керамических материалов из полидисперсных порошков алюмосиликатов с размером частиц менее 160 мкм, которые являются дешевым минеральным сырьем собственного производства [2]. Однако наличие различного рода дефектов и пор в структуре этого сырья ограничивает применение разработанных материалов в качестве электроизоляторов. Поэтому актуальной задачей является модифицирование поверхности алюмосиликатных материалов из указанного минерального сырья для увеличения механической прочности, уменьшения влагопоглощения, создания условия отсутствия смачивания (эффекта гидрофобности поверхности) с сохранением или улучшением основных электрофизических характеристик.

Целью данной работы явилось изучение влияния модифицирующих покрытий на электрофизические свойства алюмосиликатных материалов из полидисперсных порошков с размером частиц менее 160 мкм.

В ходе исследования автором решались следующие задачи:

оценить влияние суспензии фторопласта, алюмофосфатного связующего (АФС), неводных композиций компонентов полиуретана на структурные характеристики алюмосиликатной керамики, характеризующейся наличием открытой пористости;

определить электрофизические свойства модифицированной алюмосиликатной керамики в сравнении с керамикой без модификации.

Материалы и методы исследований. Образцы алюмосиликатной керамики получали технологическими приемами, включающими операции подготовки шихты, прессование образцов и спекание при температуре $1200^{\circ} \mathrm{C}$. В качестве исходных компонентов были выбраны полидисперсные порошки алюмосиликатов, полученные измельчением отходов фарфорового производства (фарфоровой посуды, ГОСТ 28390-89), и легкоплавкое глинистое сырье.

Для прессования приготавливались смеси порошка фарфорового боя (дисперсная фаза) со связкой в жидкообразном состоянии, пластификаторами и поверхностно-активным веществом (ПАВ) (дисперсионная среда).

Для изготовления экспериментальных образцов использовали системы с концентрацией твердой фазы 72 мас.\%. Исследуемые составы представлены в табл. 1.

После спекания образцы сохраняли откры-

Т а б ли ц а 1. Составы шихты

$\mathrm{T}$ a b 1 e 1. Composition of the charge

\begin{tabular}{|l|c|c|}
\hline \multicolumn{1}{|c|}{ Ингредиенты } & $\begin{array}{c}\text { Технологическое } \\
\text { назначение }\end{array}$ & $\begin{array}{c}\text { Содержание } \\
\text { компонентов, } \\
\text { мас.\% }\end{array}$ \\
\hline Фарфоровый бой & Дисперсная фаза & 72 \\
\cline { 1 - 1 } $\begin{array}{l}\text { Связка (глинистое } \\
\text { сырье) + пластификатор }\end{array}$ & $\begin{array}{c}\text { Дисперсионная } \\
\text { среда }\end{array}$ & 27 \\
\cline { 1 - 1 } \cline { 1 - 1 } Вода & \multicolumn{2}{|l}{1} \\
\cline { 1 - 1 } & &
\end{tabular}

тую пористость до $20 \%$.

Модифицирование поверхности алюмосиликатных материалов проводили окунанием экспериментальных образцов в растворы на основе водных композиций суспензии фторопласта и алюмофосфатного связующего (АФС), неводных композиций компонентов полиуретана, используемых при получении пенополиуретана, и 5\%-ного раствора поли- 
этилгидросилоксана в толуоле (гидрофобизующая кремнийорганическая жидкость, ГКЖ) с формированием на поверхности керамических материалов композиционных покрытий.

Композицию на основе суспензии фторопласта и алюмофосфатного связующего получали путем разбавления водой 60 \% водной суспензии фторопласта-4Д и смешивания ее с предварительно полученным алюмофосфатным связующим.

Состав алюмофосфатного связующего (массовая доля, \%):

$\mathrm{H}_{3} \mathrm{PO}_{4}(D=1,7) \quad 51,4$;

$\mathrm{Al}(\mathrm{OH})_{3} \quad 14,4$;

$\mathrm{H}_{2} \mathrm{O}$ остальное.

Модифицирование алюмосиликатных образцов проводили путем их окунания в раствор композиции с выдержкой в течение 10 мин и последующей сушкой в течение 30 мин при комнатной температуре и при $435 \pm 5^{\circ} \mathrm{C}$.

В основе получения композиции на основе полиуретана использовались два компонента: компонент А - полуфабрикатный лак, содержащий гидроксилсодержащий насыщенный полиэфир на основе адипиновой и фталевой кислот и диэтиленгликоля в виде 50\%-ного раствора в циклогексане, и компонент Б - метилендифенилизоцианат. Компоненты смешивались перед применением при соотношении $1: 1,3$ в растворе смеси обезвоженных толуола и изопропилового спирта. Сначала покрытие наносилось на образцы методом окунания в течение 10 мин с последующей сушкой 30 мин при комнатной температуре и при $160{ }^{\circ} \mathrm{C}$.

Затем после повторного нанесения покрытия методом окунания в течение 10 мин алюмосиликатов в ГКЖ образцы сушили 1 ч при комнатной температуре и при $180{ }^{\circ} \mathrm{C}$. Нанесение покрытия на образцы и формирование композиционных покрытий повторяли во всех случаях дважды.

Водопоглощение определяли по ГОСТ 24 409-80.

Гидрофобность образцов оценивали путем нанесения капли воды на высушенную поверхность образца по углу смачивания. Сравнительную оценку прочности керамических материалов на сжатие $\left(\sigma_{\text {сж}}\right)$ осуществляли по величине давления, разрушающего целостность образца в процессе испытания.

Для определения электрофизических свойств материалов использовали образцы алюмосиликатной керамики с композиционными покрытиями в форме таблеток диаметром $\sim 18,5$ мм и толщиной $\sim 3,0$ мм. Электрические контакты наносились серебряной пастой. Модуль импеданса $Z$ и угол сдвига фаз ф измерялись при комнатной температуре в диапазоне частот $f=20$ 1000 Гц на измерителях иммитанса E7-20 и Agilent E4980A. Амплитуда синусоидального напряжения на образце не превышала 1 В. Диэлектрическая проницаемость $\varepsilon$ и тангенс угла диэлектрических потерь $\operatorname{tg} \delta$ рассчитывались по параллельной эквивалентной схеме замещения [3].

Результаты и обсуждение. Свойства алюмосиликатных материалов с композиционными гидрофобными покрытиями, которые подвергались обработке при различных температурных режимах, представлены в табл. 2. Краевой угол смачивания измерялся после охлаждения образцов до комнатной температуры.

Известно [4-6], что АФС при пропитке пористого алюмосиликатного материала, с одной стороны, растворяет его поверхностный дефектный слой, а с другой - благодаря наличию химического сродства с материалом керамики образует при последующей обработке переходные

Т а б л и ц а 2. Свойства материалов с гидрофобными покрытиями

$\mathrm{T}$ a b 1 e 2. Properties of materials with hydrophobic coatings

\begin{tabular}{|c|c|c|c|c|c|c|c|c|}
\hline \multirow{2}{*}{ Покрытие } & \multirow{2}{*}{$\begin{array}{c}\text { Водо- } \\
\text { погло- } \\
\text { щение, \% }\end{array}$} & \multirow{2}{*}{$\begin{array}{c}\text { Прочность } \\
\text { на сжатие, } \\
\text { МПа }\end{array}$} & \multicolumn{6}{|c|}{ Краевой угол смачивания после термообработки, град } \\
\hline & & & $\begin{array}{c}\text { при } \\
200{ }^{\circ} \mathrm{C}\end{array}$ & $\begin{array}{c}\text { при } \\
300^{\circ} \mathrm{C}\end{array}$ & $\begin{array}{c}\text { при } \\
350^{\circ} \mathrm{C}\end{array}$ & $\begin{array}{c}\text { при } \\
400{ }^{\circ} \mathrm{C} \\
\end{array}$ & $\begin{array}{c}\text { при } \\
500^{\circ} \mathrm{C}\end{array}$ & $\begin{array}{c}\text { при } \\
600{ }^{\circ} \mathrm{C} \\
\end{array}$ \\
\hline Исходная керамика & 2,3 & 45,2 & \multicolumn{6}{|c|}{$*$} \\
\hline АФС-фторопласт & 0 & 77,8 & 125 & 125 & 125 & 125 & 92 & $*$ \\
\hline На основе полиуретана & 0 & 46,4 & 110 & 110 & 92 & * & $*$ & $*$ \\
\hline На основе ГКЖ & 0 & 47,3 & 115 & 105 & 95 & * & $*$ & $*$ \\
\hline
\end{tabular}

*Поверхность гидрофильна. 
структуры (вторичную фазу). Заполнение пор кристаллизующейся вторичной фазой не нарушает ранее сформированную структуру материала при согласованности коэффициентов термического расширения. При этом пропитка пористого алюмосиликатного материала АФС в 3-4 раза повышает прочность [7, 8].

Как следует из представленных результатов, покрытия на основе АФС с фторопластом ожидаемо наиболее термически устойчивы, так как не теряют своей гидрофобности до $500{ }^{\circ} \mathrm{C}$. Взаимодействие АФС с алюмосиликатной керамикой приводит к сглаживанию рельефа поверхности алюмосиликатной основы и заращиванию глубоких пор (рис. 1).
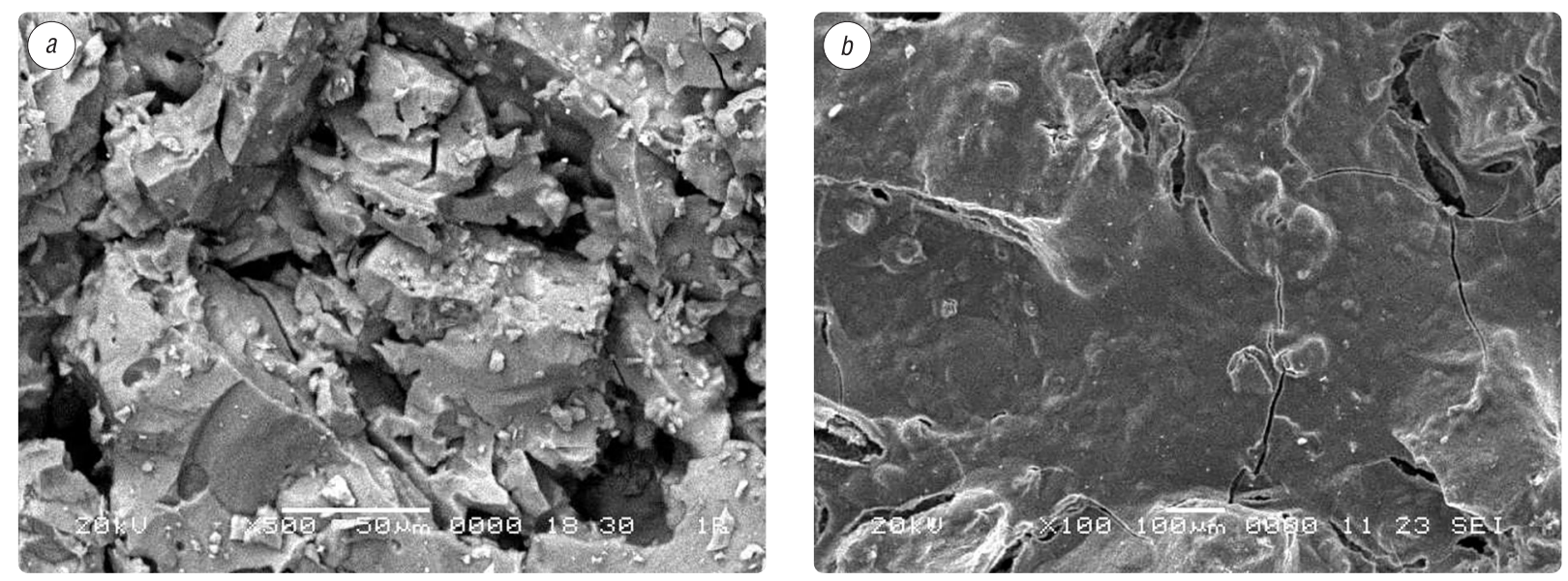

Рис. 1. Структура поверхности исходной алюмосиликатной керамики (a) и двухслойного покрытия АФС-фторопласт на ней $(b)$

Fig. 1. Surface structure of the original aluminosilicate ceramics $(a)$ and two-layer coating aluminophore ligamentfluoroplast $(b)$

На рис. 2 представлены результаты исследований электрофизических свойств образцов алюмосиликатной керамики с композиционными покрытиями гидрофобной природы. Перед измерениями образцы подвергались сушке в вакуумном шкафу при температуре $50^{\circ} \mathrm{C}$ и выдержкой 180 мин.

Видно, что композиционная структура покрытия на основе АФС, а также гетерогенность границы раздела (из-за реакционности процесса ее формирования) обуславливают наиболее выраженную частотную зависимость $\varepsilon$ и $\operatorname{tg} \delta$, а также большие диэлектрические потери композита.
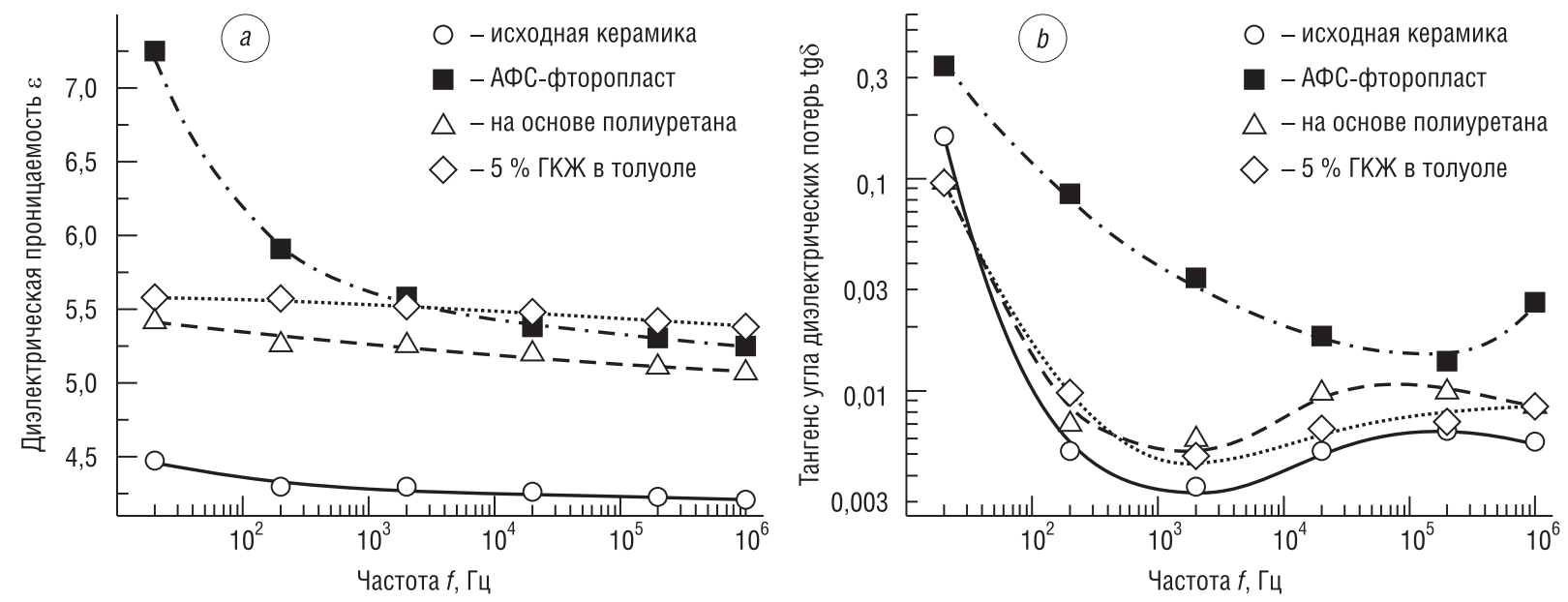

Рис. 2. Частотная зависимость: $a$ - диэлектрической проницаемости, $b$ - тангенса угла диэлектрических потерь керамических материалов с композиционными покрытиями

Fig. 2. Requency dependence: $a$ - dielectric constant, $b$ - dielectric loss tangent of ceramic materials with composite coatings 
Из представленных результатов видно, что частотные зависимости диэлектрических свойств материалов имеют немонотонный характер. При этом наблюдается уменьшение относительной диэлектрической проницаемости $\varepsilon$ с увеличением частоты переменного тока.

Как следует из рис. $2, b$, исследуемые материалы характеризуются большим диапазоном временных периодов релаксации. При наложении внешнего электрического поля слабосвязанные ионы могут переходить из одной потенциальной ямы в другую. Потенциальные барьеры, ограничивающие движение слабосвязанных ионов, значительно отличаются друг от друга, что приводит к наблюдаемому на рис. $2, b$ максимуму на кривой зависимости $\operatorname{tg} \delta$ от частоты.

Нанесение пленочных органических покрытий (на основе полиуретана, алюмофосфатного связующего и суспензии фторопласта-4Д, полиэтилгидросилоксана) приводит к формированию многослойного диэлектрического материала, в котором присутствуют поверхности раздела, отделяющие области с различными диэлектрическими свойствами. При наличии внешнего электрического поля создаются условия для миграционной поляризации между кристаллической фазой основы и аморфной фазой покрытия, обусловленной перераспределением свободных зарядов в объеме композита. Поэтому диэлектрическая проницаемость материалов с покрытиями выше диэлектрической проницаемости исходной алюмосиликатной керамики (рис. $2, a$ ).

Заключение. Изучено влияние модифицирующих покрытий на электрофизические свойства алюмосиликатных материалов из полидисперсных порошков с размером частиц менее 160 мкм. В результате проведенных исследований установлено, что материалы с композиционными гидрофобными покрытиями на основе АФС с фторопластом наиболее термически устойчивы, так как не теряют своей гидрофобности до $500{ }^{\circ} \mathrm{C}$. Кроме того, химическое взаимодействие алюмосиликатной подложки с алюмофосфатным компонентом композиционного покрытия в процессе его формирования более чем в 1,7 раза повышает прочность керамического материала. Проведение дальнейших исследований будет направлено на поиск механизмов, позволяющих улучшить электроизоляционные свойства модифицированных алюмосиликатов.

\section{Благодарности}

Автор выражает благодарность Н.И. Горбачуку (Белорусский государственный университет) за измерения электрофизических свойств.

\section{Acknowledgments}

The author is grateful to N.I. Gorbachuk (Belarusian State University) for measuring the electrophysical properties.

\section{Список использованных источников}

1. Электрофарфор [Электронный ресурс]. - Режим доступа: https://academic2.ru/\%D1 \%8D\%D0 \%BB\%D0 \%B $5 \% \mathrm{D} 0 \% \mathrm{BA} \% \mathrm{D} 1 \% 82 \% \mathrm{D} 1 \% 80 \% \mathrm{D} 0 \% \mathrm{BE} \% \mathrm{D} 1 \% 84 \% \mathrm{D} 0 \% \mathrm{~B} 0 \% \mathrm{D} 1 \% 80 \% \mathrm{D} 1 \% 84 \% \mathrm{D} 0 \% \mathrm{BE} \% \mathrm{D} 1 \% 80 \_20144030 \quad-$ Дата доступа: 19.11.2019.

2. Композиционные материалы на основе силикатов и алюмосиликатов / С. М. Азаров [и др.]. - Минск: Беларус. навука, 2014. - 175 с.

3. Параметры эквивалентных схем замещения диэлектрика [Электронный ресурс]. - Режим доступа: http://etm. mpei.ru/App_Text/tut/losses/4_2_losses.pdf_- Дата доступа: 19.11.2019.

4. Модификация свойств крупнопористой алюмосиликатной керамики олигомерными фосфатами металлов / В.Н. Макатун [и др.] // Неорганические материалы. - 2005. - Т. 41, № 1. - С. 88-92.

5. Химические основы технологии и применения фосфатных связок и покрытий / С. Л. Голынко-Вольфсон [и др.]. - Л.: Химия, Ленинград. отд-ние, 1968. - 191 с.

6. Копейкин, В.А. Материалы на основе металлофосфатов / В. А. Копейкин, А. П. Петрова, И. Л. Рашкрван. - М.: Химия, 1976. - 200 с.

7. Модифицирование поверхности высокопористых керамических материалов / В.Н. Анциферов [и др.] // Огнеупоры и техническая керамика. - 2004. - № 8. - С. 2-4.

8. Бердов, Г.И. Повышение механической прочности керамики обработкой в растворе соли / Г.И. Бердов, В. 3. Гиндулина // Стекло и керамика. - 1965. - № 12. - С. 34-36.

\section{References}

1. Electroporcelain. Available at: https://academic2.ru/\%D1 \%8D\%D0 \%BB\%D0 \%B5 \%D0 \%BA\%D1 \%82 \%D1 \% $80 \% \mathrm{D} 0 \% \mathrm{BE} \% \mathrm{D} 1 \% 84$ \%D0 \%B0 \%D1 \%80 \%D1 \%84 \%D0 \%BE\%D1 \%80_20144030 (accessed 19 November 2019) (in Russian).

2. Azarau S. M., Azarava T. A., Petyshik E. E., Branitckii G. A., Belanovisch A. L. Composite Materials Based on Silicates and Aluminosilicates. Minsk, Belarusian nauka Publ., 2014. 175 p. (in Russian). 
3. The parameters of the equivalent circuits of the dielectric. Available at: http://etm.mpei.ru/App_Text/tut/losses/4_2 losses.pdf (accessed 9 November 2019) (in Russian).

4. Makatun V. N., Rat'ko A. I., Azarov S. M., Azarova T. A., Kiticova N. V. Properties of macroporousaluminosilicate ceramics modified with oligomeric aluminum phosphates. Inorganic Materials, 2005, vol. 41 (1), pp. 82-86. https://doi. org/10.1007/s10789-005-0094-0

5. Golynko-Vol'fson S. L., Sytchev M. M., Sudacas L.G., Skoblo L. I. Chemical Fundamentals of the Technology and Application of Phosphate Binders and Coatings. Leningrad, Khimiya Publ., Leningrad branch, 1968. 191 p. (in Russian).

6. Kopeikin V. A., Petrova A. P., Rashkrvan I. L. Metallophosphate Based Materials. Moscow, Khimiya Publ., 1976. 200 p. (in Russian).

7. Anziferov V. N., Matiygullina E. V., Porozova C. E., Chafizova R. M. Surface modification of high-porous ceramic materials. Ogneupory i technitcheskaja keramica = Refractories and Technical Ceramics, 2004, no. 8, pp. 2-4 (in Russian).

8. Berdov G. I., Gindylina V. Z. Improving the mechanical strength of ceramics by treatment in a salt solution. Glass and Ceramics, 1967, vol. 24, no. 10, pp. 579-581. https://doi.org/10.1007/bf00690279

\section{Информация об авторе}

Азаров Сергей Михайлович - доктор технических наук, доцент, профессор кафедры «Технологии и методики преподавания», Белорусский национальный технический университет (пр. Независимости, 65, 220013, Минск, Республика Беларусь).

\section{Information about the author}

Siarhei M. Azarau - D. Sc. (Engineering), Associate Professor, Professor of the Department of Technology and Methods of Teaching, Belarusian National Technical University (65, Nezavisimosti Ave., 220013, Minsk, Republic of Belarus). 